\title{
APPLYING RECOGNITION OF EMOTIONS IN SPEECH TO EXTEND THE IMPACT OF BRAND SLOGAN RESEARCH
}

\author{
Charles S Chien \\ School of Management and Development, Feng Chia University, Taiwan
}

Wan-Chen Wang, Luiz Moutinho

School of Business and Management, University of Glasgow, UK

Yun-Maw Cheng, Tsang-Long Pao, Yu-Te Chen, Jun-Heng Yeh

Department of Computer Science and Engineering, Tatung University, Taiwan

\begin{abstract}
How brand slogans can influence and change the consumers' perception of image of products has been a topic of great interest to marketers. However, it is a non-trivial task to evaluate how brand slogans affect their customers' emotions and how the emotions influence the customers' perceptions of brand images. In this paper we demonstrate the Slogan Validator to evaluate brand slogans by analyzing the speech signais from customers' voiced slogans. it is arguably the first speech signal based analysis of brand slogans. Our intention was to evaluate whether the signal-based emotion recognition technique can complement the traditional research methodologies, such as survey research method dealing with selfreported measurements, phenomenological research based on physiological measures, and semi-structured interviews, in order to increase the overall effectiveness of advertising copy strategy. The preliminary results of the experiment show that the Slogan Validator yields high consistency with the participants' actual perceptions of the brand slogans chosen for this research.
\end{abstract}

Keywords: brand slogan; recognition of emotions; speech recognition; machine learning.

\section{INTRODUCTION}

Slogans are embodiments of brand essences. They can induce emotional responses that guide consumers toward or away from certain products (Norman, 2004). This is the reason that the design of brand slogans is so important in the

Correspondence Address: Yun-Maw Cheng, Department of Computer Science and Engineering, Tatung University, Taiwan, 104 R.O.C.; e-mail: kevin@ttu.edu.tw 
field of commerce. In addition, voice expression is one of our innate social features to signal our emotional status in order to communicate with others. Although facial expression and body posture also share similar characteristics, voice expression is used most frequently in our everyday communication (Picard, 1997). Voice of slogan could be a very natural means of expression that reflects our emotion inclining to a certain brand (Dahlen and Rosengren, 2005). Capturing the signal attributes of voice of slogan through the signal-based measurement could possibly provide more insightful data for recognition of emotions than recallbased data from questionnaire approach.

To brand is to burn. Brand slogans are exploited as a marketing tool to facilitate a voice keynote for message diffusion among the consumer market. They can be seen as a powerful positioning tool for company's marketing efforts. A number of well known brand slogans, such as just do it; always Coca-Cola, have been confirmed to have greatly contributed to the brand equity (Aaker, 2004; Aaker and Jacobson, 2001; Mathur and Mathur, 1995). As noted by the previous research, brand slogans can be served as a platform for evoking and reminding the desired emotions to brand the product perceptions (Ennis and Zanna, 1993). It is argued that emotional tones can attract attention and recall customer's memory about their experiences with the represented brands. In advertising campaigns, using brand slogans primed ${ }^{2}$ by designed emotions is a way to brand consumers' perceptions. Marketers need to adopt appropriate brand slogans to manage their brands in order to have the brands speak to their consumers on an emotional bond level and win the attention.

Research into recognition of emotions in speech is increasingly attracting attention within the fields ranging from psychology, linguistics, to computer science. The intention is to provide a seamless and efficient interface based on this technology for users work with computers. As far as we are aware, most of previous approaches in this field have focused on the innovative system architecture. In contrast, we were motivated to find novel use of this technology. Our aim is to determine whether the application based on this technology might help to better understand brand slogans. The work is inherently multidisciplinary. The co-authors have diverse backgrounds as listed in the affiliations.

\section{EMOTIONS AND ADVERTISING}

The majority of advertising research has assumed that consumers have an underlying economic rationality (Vakratsas and Ambler, 1999). The probable

\footnotetext{
${ }^{3}$ Priming exists when "recently and frequently activated ideas come to mind more easily than ideas that are not recently or frequently activated" (Fiske and Taylor, 1984). It has been used by psychologists to keynote the naming of objects (Higgins et al., 1985).
} 
effectiveness of advertising has been determined by measuring the attention or interest in the ad (Heath and Hyder, 2005). However, it is suggested that it is the emotional and not the rational content in communication that drives brand relationship (Bornstein, 1989; Heath et al., 2006).

Although Cabanac (2002) highlighted that there is no consistency in the literature on a definition of emotion. According to Chamberlain and Broderick (2007), the definition of emotion has been widely discussed and several attempts have been made to tighten the construct (Russell and Barrett, 1999) and there is considerable agreement (e.g., Bagozzi et al., 1999; Oately, 1992) that "emotional responses are relatively brief, phasic events that are accompanied by physiological processes, often expressed physically (e.g., in gestures, posture, facial features) and may result in specific actions to affirm or cope with the emotion depending on its nature and meaning for the person experiencing the emotion" (Chamberlain and Broderick, 2007, p. 202). There are two main streams of the theoretical debate regarding the conceptualization of emotions. One psychological perspective is that emotions are discrete entities. However, this perspective has been criticized on the basis that individuals may experience more than one emotion at the same time. Another perspective identifies emotion as a global feeling construct (Shapiro et al., 2002) where distinct emotional states can be described by their position on two fundamental dimensions: arousal and valence. "Valence is defined as pleasantness or hedonic value and arousal is defined as bodily activation" (Barrett, 1998, p. 579). This school of thought stated that each dimension of valence and arousal may affect consumer behavior differently (Shapiro et al., 2002) and has been widely accepted by many researchers (Chamberlain and Broderick, 2007). However, the complicated content of emotions is still not clear in the construct of emotions. Thus, if the significant features which are related to emotions in relation to brand attitudes and slogans can be found, then, the effectiveness of advertising strategy can be improved.

\section{BRAND SLOGANS}

Slogans have long been used as a constituent in advertising campaigns (Reece, 1984). In the USA, researchers estimated that consumers would have viewed about 350,000 advertisements by the age of 18 . This means that advertising is one of the most widely shared experiences in the lives of most people (Wright and Snow, 1980).

An advertising slogan is an expression that is written for its memory potential and is often repeated to increase its recall (Wells et al., 1989) and encourage the consumer to remember the sponsor's particular brand when confronted with a set of alternatives (evoked set) (Katz and Rose, 1966). As used in contemporary 
advertising campaigns, a slogan "is a short phrase used to help establish an image, identity, or position for an organization to increase memorability" ( 0 'Guinn, et al., 2003 , p. 428). In branding literature, a slogan is typically defined on the core of its common purpose: "Slogans are short phases that communicate descriptive or persuasive information about a brand" (Supphellen and Nygaardsvik, 2002, p386). A slogan may be surprising or unexpected and may use alliteration, parallel construction, rhyme, or rhythm (Wells et al., 1989).

Slogans may have positive effects on their brands and may work as carriers of brand equity (Dahlen and Rosengren, 2005; Rosengren and Dahlen, 2006). Mathur and Mathur (1995) indicated that announcements of advertising slogan changes affected firm's annual profits by an average amount of US $\$ 6-8 \mathrm{~m}$. Nevertheless, it has been arguing that most people do not care about advertising or brand slogans. Studies indicated that $90 \%$ of all advertising is viewed as not credible (Ogden, 2001). As the global business environment is more competitive and changes more rapidly, the power of advertising slogans is less sure.

\section{METHODOLOGIES OF EMOTION RESEARCH}

There are two major types of methods to measure emotions: self-reported measurements and physiological measurements. Both methods have been applied in advertising research to record emotional reactions to advertising stimuli. However, the two methods are basically different. Self-reported measurements focus on thoughtful reflections about the emotions felt with respect to an advertising stimulus. On the contrary, physiological measurements focus on continuous emotional reactions that are not distorted by higher cognitive processes (Poels and Dewitte, 2006).

Self-reported measurements have been widely used to measure emotional reactions to advertising. Self-reported measurements record the respondent's subjective feeling. According to Stout and Leckenby (1986), a "subjective feeling" can be defined as the consciously felt experience of emotions as expressed by the person. Generally, there are three kinds of self-reported methods that all measure subjective feelings: visual self-report, verbal self-report and moment-to-moment rating. Self report scales of subjective experiences are the most commonly used procedure in the emotion research. In addition, there are four broadly used measurement instruments of consumer emotion: pleasure-arousal-dominance (PAD) dimensions of emotions (Mehrabian and Russell, 1974); feelings towards ads (Edell and Burk, 1987); standardised emotional profile (SEP) (Holbrook and Batra, 1987); and consumption emotions set (CES) (Richins, 1997). These four scales are all used to measure consumers' emotional responses (Chamberlain and Broderick, 2007).

\section{8}


Self-reported measurements contribute to the benefit of being user friendly and rapid measures of emotional response. They do not need complicated techniques or programs, and it is possible to administer emotional feelings to a comparatively large set of advertising stimuli. Thus, a self-reported measurement is a cheap method that is very suitable for large-scale research. Owing to these benefits, self-report has always been a very well-liked method for practitioners (Mehta and Purvis, 2006; Poels and Dewitte, 2006).

Yet, self-reported measurements still suffer from a vital restriction referred to as "cognitive bias." A great quantity of research indicated that individuals are not fully aware of a lot of things they do in everyday life but rather process information automatically and behave spontaneously in many situations (Bargh and Chartrand, 1999; Chamberlain and Broderick, 2007; Chartrand, 2005; Zaltmann, 2003; Winkielman et al., 2005). Consequently, although these lower-order emotions may have a significant influence on our decisions, selfreported measurements derived from subjective feelings may not always be able to access lower-order emotions in a correct way. It has been claimed that the self-reported measurements reflect the participants' beliefs about what they feel instead of the contents of conscious feeling (Chamberlain and Broderick, 2007; Dennett, 1991; Frijda et al., 1995; Hazlett and Hazlett, 1999; Ortony et al., 1988). In addition, social desirability concerns can misrepresent results. Particularly for sensitive topics such as erotica, racial issues, gender and age issues participants may not always willing to inform how they really feel (King and Bruner, 2000).

Even though measurement instruments of consumer emotion described above have proved useful in the contexts for which they were developed, several restrictions in their application to the study of consumer emotions must be acknowledged. Firstly, most of the measures include some expressions not familiar to many consumers and some measures are also puzzling. Secondly, all of the scales take no notice of some of the emotions that are particularly central in people's lives. Finally, the suitability of using existing measures to assess emotions elicited in consumption situations is unidentified.

Since the validity of self-report for measuring lower-order emotions is often influenced by cognitive or social desirability limitations, the measurement of autonomic reactions can conquer this problem as they measure emotional responses outside the respondents' control. Some researchers emphasized the need for measures of emotion to go beyond self-reported measurements (Bagozzi et al., 1999) and declared that "autonomic nervous system and other physiological processes" at least accompany subjectively felt emotions (Oatley, 1992, p.21). Recently, several techniques have been developed to capture autonomic reactions. Skin conductance, heart rate, facial expression and neuroscience are four wellknown physiological measures. 
Given the significance of emotions in the advertising process, accurate measurement of emotions is crucial. Yet, advertising literature is not straightforward on what measurement instrument provides the most valid emotion measurement. However, measuring emotions is not easy. Over many years, emotional reactions to advertising have been measured in several ways (Bagozzi, et al., 1999). Although most authors acknowledge the importance of emotions in the advertising process, Vakratsas and Ambier (1999) argued that there is more work needed to standardize measurement methodologies of emotion in advertising. Furthermore, there is a significant need to investigate the validation of current measures of emotions applied in a marketing context. It may be required to compliment other methods with selfreported measurements to access both the conscious and subconscious experiences of the consumer (Chamberlain and Broderick, 2007; Hazlett and Hazlett, 1999; Poels and Dewitte, 2006). The use of oral language is a more primary and general cognitive ability than reading and writing. It is believed that spoken language predates written language by no less than 25,000 years, and probably much more than that (Pinker, 1994). Thus, it would be most obvious with spoken language if a link exists between language processing and emotion (Wurm et al., 2001).

\section{COMMON APPROACH TO THE EVALUATION OF BRAND SLOGANS}

The importance of the notion of brand slogans notwithstanding, marketers have been provided with limited insight into how to measure it. Considerable discussions among marketers have focused on traditional questionnaire responses. The questionnaire approach has been effective in measuring attitude tendency behind the behavior intention. However, when applying to measure emotion data by asking respondents' recalled feelings, respondents may have difficulty to respond to questions regarding how they feel about a brand. It is because they are rarely called upon to articulate such feelings. Moreover, questionnaires that exploit adjective checklists or other forms of structured questions often yield biased answers. Responses can be different from those elicited when subjects are aided by lists or predetermined response categories (Tull and Hawkins, 1987). Emotion is often reflected in physical responses that reside at the level below consciousness. In the recent development of marketing thoughts, it has been emphasized the need for techniques that can help the researchers and marketers to get below the surface to measure emotion. A number of researchers emphasize the need for measures of emotion to go beyond self-reported measurements (e.g., Babin et al., 1998; Bagozzi et al., 1999; Oatley, 1992) and have called for collaboration with other research fields to advance consumer behavior research in the study of emotion (e.g., Bagozzi et al., 1999; Lee et al., 2007). An alternative approach suggested in this paper is through the analysis of customers' voice expression of brand slogans. 


\section{OBJECTIVES AND METHODS OF SPEECH SIGNAL BASED EVALUATION OF BRAND SLOGANS}

There have been relatively few attempts to develop computer-based tools specifically to support evaluation of brand slogans. This is mainly because that few computer scientists participate in market, and more specifically, brand slogan research. In addition, research in this field tends to depend on semantic of words that composite of brand slogans, as it is arguably the easiest way to evaluate emotions embedded in slogans. As mentioned, questionnaire analysis is the most common method of assessing slogans although it is not necessarily the most effective. Signal-based evaluation tools address some of the limitations of questionnaire approach. For example, it is possible to capture and analyze speech signals of slogans and elicit emotions from the signal data. This is a more natural means than analyzing recalled attitude data from questionnaire responses. The development of applications of this type requires considerable engineering skills. This raises the entry level of discovering more about the feasibility and effectiveness of this approach to marketers.

The following describes the development of the computer-based tool, Slogan Validator, and how it functions to present emotions embedded within brand slogans. The hope is to provide marketers an easy to operate and comprehend computerbased tool to evaluate brand slogans.

\section{EMOTIONAL SPEECH CORPUS}

For the initial stage, an emotional corpus needs to be built up in order to form a base for eliciting emotions from speech signals. In this paper, five primary emotions, anger, happiness, sadness, boredom, and neutral (unemotional), are investigated (Murray and Arnott, 1993). We invited eighteen males and sixteen females to portray these emotional states. Twenty different prompting sentences with one to six words were designed. These sentences are purposely neutral and meaningful so the participants can easily express them with these emotions. This exercise yielded a corpus containing 3,400 utterances. Each utterance was recorded in 8-bit PCM with a sampling frequency of $44.1 \mathrm{k} \mathrm{Hz}$. This preliminary corpus is then evaluated by human judgers in order to filter out ambiguous emotional utterances for further recognition analysis. Table 1 shows the human judger performance confusion matrix. The rows and the columns represent the simulated and the evaluated categories respectively. For instance, the first row shows that $89.6 \%$ of utterances portrayed as angry were evaluated as true angry, $4.3 \%$ as happy, $0.9 \%$ as sad, $0.8 \%$ as bored, $3.5 \%$ as neutral, and $0.9 \%$ if none of the above. 
From the preliminary corpus we only adopted the utterances that can be recognized as portraying the given emotion by the human judgers. It is, therefore, we divide the recorded utterances into different subsets in response to the recognition accuracy as listed in the Table 1. We then annotate these subsets as D80, D90 and D100. These stand for the recognition accuracy of at least $80 \%, 90 \%$, and $100 \%$ respectively, as listed in the Table 2 . The D80 subset is relatively close to the human recognition rate (Bänziger and Scherer, 2005). Table 2 also shows the distribution of utterances among the given emotion categories for the corpus.

TABLE 1

Human Judger Performance Confusion Matrix

\begin{tabular}{|c|c|c|c|c|c|c|}
\hline & Angry & Happy & Sad & Bored & Neutral & Others \\
\hline Angry & $\mathbf{8 9 . 6}$ & 4.3 & 0.9 & 0.8 & 3.5 & 0.9 \\
\hline Happy & 6.7 & $\mathbf{7 3 . 2}$ & 3.3 & 2.4 & 13.6 & 0.9 \\
\hline Sad & 2.9 & 1.0 & $\mathbf{8 2 . 8}$ & 9.3 & 3.3 & 0.7 \\
\hline Bored & 1.3 & 0.4 & 8.6 & $\mathbf{7 5 . 2}$ & 13.7 & 0.9 \\
\hline Neutral & 1.7 & 0.9 & 1.6 & 12.3 & $\mathbf{8 3 . 5}$ & 0.1 \\
\hline
\end{tabular}

TABLE 2

The Size of Each Subset

\begin{tabular}{|c|c|c|c|}
\hline Data set & D80 & D90 & D100 \\
\hline Number of utterces & 570 & 473 & 283 \\
\hline
\end{tabular}

\section{RECOGNITION ARCHITECTURE}

The core of the Slogan Validator is the underlying recognition architecture. Fig. 1 shows the emotion recognition architecture based on the K-NN (K-Nearest Neighbor) method. During the pre-processing stage, it is firstly to locate the endpoints of the input speech signal. The speech signal is high-pass filtered in order to emphasize the importance of high frequency components. Secondly, the speech signal is partitioned into pieces of frames, which consist of 256 samples each. Each frame overlaps with the adjacent frames by 128 samples. Thirdly, apply the hamming window to each frame to minimize the signal discontinuities both at the beginning and the end of each frame. Each windowed frame is then converted into several types of parametric representations for further recognition purposes. 
FIGURE 1

Block diagram of K-NN based emotion recognition system

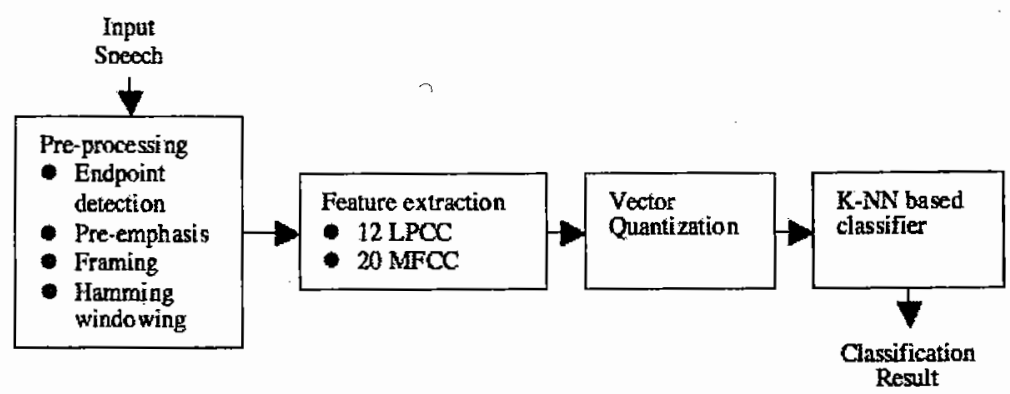

The next stage is the speech feature extraction. It is arguably the most challenging issue when building an emotion recognition system for speech signa! (Banse and Scherer, 1996; Petrushin, 2002; Schuller et al., 2003). In this paper, we exploit the regression selection method to identify possible candidates from more than 200 speech features, in an attempt to discover a suitable combination of extracted features. The most effective candidates are formants (F1, F2 and F3), Linear Predictive Coefficients (LPCs), Linear Prediction Cepstral Coefficients (LPCCs), Mel-Frequency Cepstral Coefficients (MFCCs), the first derivative of MFCC (dMFCCs), the second derivative of MFCC (ddMFCCs), Log Frequency Power Coefficients (LFPCs), Perceptual Linear Prediction (PLP) components, and RelAtive SpecTrAI PLP (Rasta-PLP) components (Tato et al., 2002; Kwon et al., 2003). Due to the redundant information, the forward feature selection (FFS) and the backward feature selection (BFS) are carried out to extract the most representative features.

As for the feature vector quantization stage, 20 MFCCs and 12 LPCCs of each speech frames are processed to elicit the parameters of each utterance as the feature vector. We utilize a vector quantization method (Pao et al., 2005) to apply the mean of feature parameters corresponding to each frame in one utterance. This is to form a feature vector $Y$ with 32 parameters listed as follows:

$Y=\left[p_{1} p_{2} \ldots p_{32}\right]$, where $p_{i}$ is the mean value of the $i$ th parameter of all frames.

In K-NN decision rule, when a new unlabeled data $x$ joins, $k$ neighbors of the training space nearest to the unlabeled data will make certain decisions based on some distance measure. Let $k$ prototypes nearest to $x$ as $N_{k}(x)$, and $c(y)$ as the class label of $y$. Then the subset of the nearest neighbors within class $j \in\{1, \ldots, I\}$, where $l$ is the number of labelled classes, is: 


$$
N_{k}^{j}(x)=\left\{y \in N_{k}(x) \text { and } c(y)=j\right\}
$$

The classification result, $j^{*} \in\{1, \ldots /\}$, is then decided by a majority vote as:

$$
j^{*}=\arg \max _{j}\left|N_{k}^{j}(x)\right|
$$

The Modified-KNN (M-KNN) is a classification technique based on K-NN decision rule (Pao et al., 2005). When a new unlabelled data $x$ joins, M-KNN employs $k$ neighbors nearest to the unlabeled data in each class $j$ and determines their Euclidean distances $d_{i}^{j}, i=1, \ldots, k$, within the training space. Finally, the classification result is obtained by summing up the distance values in each class and picking up the smallest one, that is:

$$
j^{*}=\arg \min _{j} \sum_{j=1}^{k} d_{i}^{j}
$$

The weighted D-KNN (Distance K-NN) (Pao et al., 2005), which combines M-KNN with weighting scheme, is applied to evaluate emotions from speech data. The purpose of weighting series is to improve classification accuracy of the classifier by assigning lower weights to the neighbors that provide less relevant information for classification and higher weights to reverse neighbors. Among the $k$ nearest neighbors in class $j$, we know that $d_{i}^{j}$ is the most important. Let $w_{i}$ be the weight of the ith nearest samples. The classification result is defined as:

$$
j^{*}=\arg \min _{j} \sum_{i=1}^{k} w_{i} d_{i}^{j}
$$

In this paper, Fibonacci series is adapted as the weighting function. Table 3 shows partial results of each measured distance derived by the weighted D-KNN classifier. As can be seen, the emotional expression of this utterance can be aware of anger in chief.

\section{VISUALIZATION OF EMOTIONS}

To visualize the evaluated results, we take the radar chart approach. A radar chart is useful when several factors need to be examined at once and presented simultaneously. We choose this presentation technique for pragmatic reasons and further studies could compare this approach with alternative data visualization techniques. However, we do not deal with visualization techniques in this paper, as this is the research area in its own right. In the Slogan Validator, each of the axes of the radar chart represents emotions in the designated key performance 
TABLE 3

Partial Evaluation Result

\begin{tabular}{|c|c|c|c|c|c|}
\hline Emotion & Anger & Happiness & Sadness & Boredom & Neutral \\
\hline Evaluation Value & 1.00 & 0.60 & 0.58 & 0.27 & 0.50 \\
\hline
\end{tabular}

FIGURE 2

Radar chart of a sample utterance with angry emotion

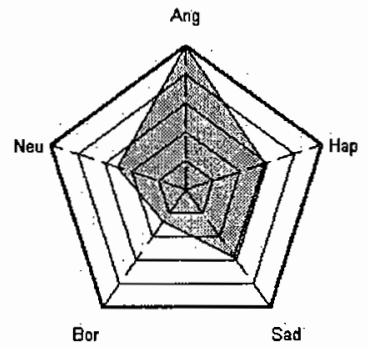

dimensions. Fig. 2 shows the radar chart in the Slogan Validator. The chart shows that this evaluated utterance is expressed close to anger, and the intensity of anger is greater than the other emotions. Moreover, this utterance is also expressed with slightly happy and sad that the Slogan Validator can perceive.

There is no theoretical constraint to the number of axes utilized in radar charts. This flexibility helps present more emotions that are derived from detailed study of design of slogans and remains simplicity to be easily interpreted in one big picture. It is important to note that a radar chart may become difficult to understand and interpret if there are too many axes within it.

Figure 3 demonstrates the user interface of the Slogan Validator. The source of the speech signals can be selected from the source frame. It can either be the recorded utterances in the corpus or the real-time recorded utterances from the users. The evaluation results are then plotted on the radar chart. The message frame shows the progression of the evaluation or error messages. The result frame displays the recognition result. Some of the user interface of the Slogan Validator did not satisfy generally accepted Human-Computer Interaction $(\mathrm{HCl})$ design principles. However, the emphasis on this prototype application is in an attempt to demonstrate that this application functions and can act as an alternative method for evaluating brand slogans. Further development and improvement could be carried out to address the current user interface issues. 
FIGURE 3

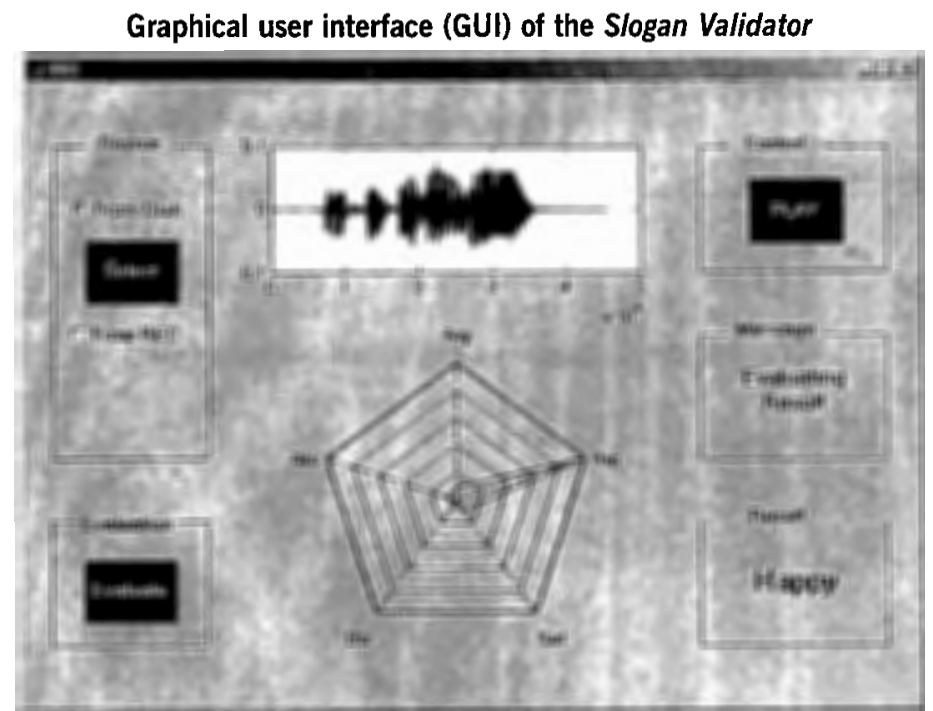

\section{USING THE SLOGAN VALIDATOR TO BENCHMARK BRAND SLOGANS}

A pilot study was launched to evaluate consumer's emotions towards certain brand slogans by applying the Slogan Validator. Two brand slogans were chosen on the bases of brand awareness, brand associations, and degree of loyalty. These brand slogans are: (1) "McDonald is all for you" spoken for fast-food chains McDonald, (2) "Health! Beauty! more and more" for drug-store chains Watsons. We invited eight participants (four males and four females) to record their voice of slogans for the given brands. Participants were asked to watch TV advertisings that promote the brand slogans for each brand. They then speak out each brand slogan in a temporary recording room where ambient noise can be avoided in order to form a calm surrounding. Each voice-recording subject took about fifteen to twenty minutes to complete.

\section{OBSERVATIONS}

The chosen brands are all popular to a certain degree in the Taiwan market. In term of advertising theme promoted in the slogans, McDonald is in efforts to position an umbrella theme for promoting association of warm, caring, and happy when consumers experiencing with its food and services. It applies the emotional appealing to their all-over services experiences. Watsons, on the other hand, emphasizes the theme of desire, attractive, and zest. It emphasizes on rational 
appealing to utilitarian attributes. The degree of loyalty on these brands is varied among different segments of consumers. These are summarized in the Table IV.

TABLE 4

Attributes of Evaluated Brand Slogans

\begin{tabular}{|c|c|c|c|c|}
\cline { 2 - 5 } \multicolumn{1}{c|}{} & Brand slogan & $\begin{array}{c}\text { Brand } \\
\text { awareness }\end{array}$ & Associated emotion & Brand loyalty \\
\hline McDonald & $\begin{array}{c}\text { McDonald is } \\
\text { all for you }\end{array}$ & high & warm, caring, happy & $\begin{array}{c}\text { Medium } \\
\text { involvement }\end{array}$ \\
\hline Watsons & $\begin{array}{c}\text { Health! } \\
\text { Beauty! More } \\
\text { and more }\end{array}$ & moderate & $\begin{array}{c}\text { desire, attractive, } \\
\text { zest } \\
\text { involvement }\end{array}$ \\
\hline
\end{tabular}

\section{RESULTS AND DISCUSSION}

The result of our experiment shows several interesting findings. The emotion radar charts show significant visual differences between the slogans of McDonald and Watsons. As shown in Fig. 4, the twisted pentagon shape of McDonald slogan suggests the planned position delivers combinations of overall emotions with particularly priming through happiness. Such result is consistent with the planned emotional theme of McDonald's slogan without considering any semantic-based measurement. The overall emotion reflecting peripheral route of information process can be partially evidenced in the radar chart, too. In consumer's mind-set, peripheral route of information process is suitable to mirror interpersonal emotion type in the McDonald's slogan. The spear shape of Watsons slogan suggests the designed position is less on happiness but more on articulate utilitarian emotion type. This could be categorized as an utterance close to anger in the given emotions. The articulate emotion reflecting central route of information process can be partially evidenced in this visually plotted result. In addition, the variations among the participants' preferences are also can be seen in the findings. For example, in Fig. 5 , the subject, $M-1 M$, spoke out McDonald slogan with the speech features revealing more on happiness parameter than other parameters. In a follow-up interviewing, comparing to other participants, he admitted that he is a frequent customer for $\mathrm{McD}$ onald. Although this is only a pilot study to apply emotion recognition from speech signal to measure brand slogans, this study shed a light on a highly possible avenue leading to contribute the understanding of brand slogan strategy. 
The average result of McDonald slogan (left) and Watsons (right)

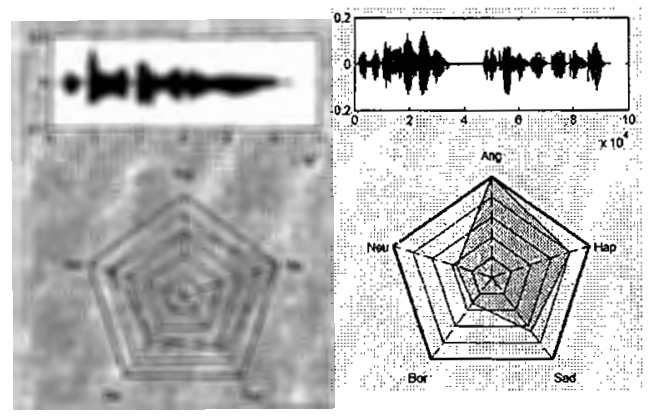

FIGURE 5

Feedback from the participant M1-M (Gender-Brand: Male Participant 1-McDonald)

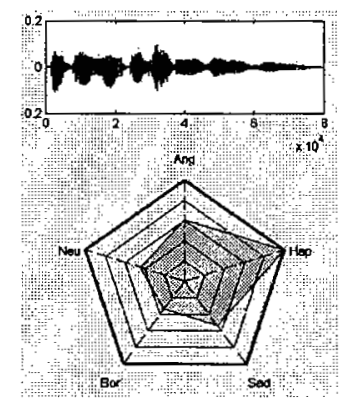

\section{CONCLUSIONS AND FUTURE WORK}

In this paper, we describe the Slogan Validator, a tool for evaluating brand slogans. It is built upon the technique of recognition of emotions from speech signals, which provides an intuitive and nature method to analyze brand slogans compared to the traditional recalled attitude data from questionnaire responses. The aim is to help marketers evaluate whether their brand slogans as of they were designed and identify one with a potential of projecting emotional positive effects to their target customers in a relatively short time. The design of the tool was informed by a series of consultations with business and marketing professionals who are familiar with brand slogan and consumer behavior related issues. They provide valuable insights into the types of information that form the base of the Slogan Validator. We also conducted an evaluation of brand slogans using this application. The preliminary results of the experiment show that the Slogan Validator yields high consistency with the participants' actual perceptions of the brand slogans chosen for this research. 
Recognition of emotions in speech is one of the challenges in the field of speech signal processing research. In particular, the selection of a feature set is arguably the most critical part when developing application of this kind. The underlying architecture of the Slogan Validator exploits 20 MFCCs (Mel Frequency Cepstral Coefficients) and 16 LPCCs (Linear Predictive Cepstral Coefficients), which are extracted from speech signals and selected as the features to identify emotional states of the users. We are currently working on finding more efficient features for our recognition architecture. In the meantime, we plan to disseminate the Slogan Validator to researchers and marketers who are more interested in the application scenario than the underlying technical implementation. The hope is to obtain the first hand comments from these experts in order to evolve the current prototype.

\section{References}

Aaker, D. A. (2004). Strategic Market Management 7th ed. New York : Wiley.

Aaker, D. A. \& Jacobson, R. (2001). The Value Relevance of Brand Attitude in High-Technology Markets. Journal of Marketing Research (JMR), 38, 485-493.

Babin, B. J., Darden, W. R., University, L. S., Shreveport, Lousiana, \& Babin, L. A. (1998). Negative Emotions in Marketing Research: Affect or Artifact? Journal of Business Research, 42, 271-285.

Bagozzi, R. P., Gopinath, M., \& Nyer, P. U. (1999). The Role of Emotions in Marketing. Journal of the Academy of Marketing Science, 27, 184-206.

Banse, R. \& Scherer, K. R. (1996). Acoustic Profiles in Vocal Emotion Expression. [Miscellaneous Article]. Journal of Personality \& Social Psychology, 70, 614-636.

Banziger, T. \& Scherer, K. R. (2005). The role of intonation in emotional expressions. Speech Communication, 46, 252-267.

Bargh, J. A. \& Chartrand, T. L. (1999). The Unbearable Automaticity of Being. [Miscellaneous Article]. American Psychologist, 54, 462-479.

Barrett, L. F. (1998). Discrete Emotions or Dimensions? The Role of Valence Focus and Arousal Focus. Cognition \& Emotion, 12, 579-599.

Bornstein, R. F. (1989). Exposure and Affect: Overview and Meta-Analysis of Research, 19681987. [Review]. Psychological Bulletin, 106, 265-289.

Cabanac, M. (2002). What is Emotion? Behavioural Processes, 60, 69-83.

Chamberlain, L. \& Broderick, A. J. (2007). The Application of Physiological Observation Methods to Emotion Research. Qualitative Market Research, 10, 199-216.

Chartrand, T. L. (2005). The Role of Conscious Awareness in Consumer Behavior. Journal of Consumer Psychology, 15, 203-210.

Dahien, M. \& Rosengren, S. (2005). Brands Affect Slogans Affect Brands? Competitive Interference, Brand Equity and the Brand-Slogan Link. Journal of Brand Management, 12, 151-164.

Dennett, D. (1991). Consciousness Explained. Boston, MA: Little/Brown.

Edell, J. A. \& Burke, M. C. (1987). The Power of Feelings in Understanding Advertising Effects. Journal of Consumer Research, 14, 421.

Ennis, R. \& Zanna, M. P. (1993). Attitudes, Advertising, and Automobiles: A Functional Approach. Advances in Consumer Research, 20, 662-666.

Fiske, S. \& Taylor, S. E. (1984). Social Cognition Reading. MA: Addison-Wesley.

Frijda, N. H., Markam, S., Sato, K., \& Wiers, R. (1995). Emotion and Emotion Words. In J.A. Russell, J. M. Fernandez-Dols, \& A. S. R. Manstead (Eds.), Everyday Conceptions of Emotion (pp. 121-143). New York, NY: Kluwer Academic Publishers. 
Hazlett, R. L. \& Hazlett, S. Y. (1999). Emotional Response to Television Commercials: Facial EMG vs. Self-Report. Journal of Advertising Research, 39, 7.

Heath, R., Brandt D., \& Nairn, A. (2006). Brand Relationships: Strengthened by Emotion, Weakened by Attention. Journal of Advertising Research, 46, 410-419.

Heath, R. \& Hyder, P. (2005). Measuring the Hidden Power of Emotive Advertising. International Journal of Market Research, 47, 467-486.

Higgins, E. T., Bargh, J. A., \& Lombardi, W. (1985). Nature of Priming Effects on Categorization. Journal of Experimental Psychology, Learning, Memory, and Cognition, 11, 59-69.

Holbrook, M. B. \& Batra, R. (1987). Assessing the Role of Emotions as Mediators of Consumer Responses to Advertising. Journal of Consumer Research, 14, 404.

Katz, M. \& Rose, J. (1969). Is Your Slogan Identifiable? Journal of Advertising Research, 9, 21-26.

King, M. F. \& Bruner, G. C. (2000). Social Desirability Bias: A Neglected Aspect of Validity Testing. Psychology \& Marketing 17[2], 79-103. Ref Type: Journal (Full)

Kwon, O. W., Chan, K., Hao, J., \& Lee, T. W. (2003). Emotion Recognition by Speech Signais. In Bourlard, H.(eds.): Proceedings of Eurospeech 2003.Geneva Switzerland (pp. 125-128).

Lee, N., Broderick, A. J., \& Chamberlain, L. (2007). What is 'neuromarketing'? A discussion and agenda for future research. International Journal of Psychophysiology, 63, 199-204.

Mathur, L. K. \& Mathur, I. (1995). The Effect of Advertising Slogan Changes on the Market Values of Firms. Journal of Advertising Research, 35, 59-65.

Mehrabian, A. \& Russell, J. A. (1974). An Approach to Environmental Psychology. Cambridge MA: MIT Press.

Mehta, A. \& Purvis, S. C. (2006). Reconsidering Recall and Emotion in Advertising. Journal of Advertising Research, 46, 49-56.

Murray, I. \& Arnott, J. L. (1993). Towards the Simulation of Emotion in Synthetic Speech: A Review of the Literature on Human Vocal Emotion. Journal of the Acoustic Society of America, 93, 1097-1108.

Norman, D. A. (2004). Emotional Design: Why We Love (or Hate) Everyday Things. New York: Basic Books.

O'Guinn, AllenT.C., \& Semenik, R. (2003). Advertising. New York: South-Western College Publishing.

Oately, K. (1992). The Psychology of Emotions. Cambridge: Cambridge University Press.

Ogden, M. (2001). The Business Journal - Serving the Triangle's Business Communities (Raleigh, NC) Marketing truth: Hearing is believing.(Word-of-mouth better than advertising)(Brief Article). $16,17$.

Ortony, A., Clore, G. L., \& Collins, A. (1988). The Cognitive Structure of Emotions. New York, NY: Cambridge University.

Pao, T. L., Chen, Y. T., Yeh, J. H., \& Chang, Y. H. (2005). Emotion Recognition and Evaluation of Mandarin Speech Using Weighted D-KNN Classification. In Wang, J.F.(ed.): Proceedings of ROCLING 2005.Taiwan (pp. 203-212).

Pao, T. L., Chen, Y. T., Yeh, J. H., \& Liao, W. Y. (2005). Detecting Emotions in Mandarin Speech. In Computational Linguistics and Chinese Language Processing (pp. 347-362).

Petrushin, V. (2002). Creating Emotion Recognition Agents for Speech Signal. In K.Dautenhahn, A. H. Bond, L. Canamero, \& B. Edmonds (Eds.), Socially Intelligent Agents: Creating Relationships with Computers and Robots ( Dordrecht, The Netherlands Dordrecht, The Netherlands: Kluwer Academic Publishers.

Picard, R. W. (1997). Affective Computing. The MIT Press.

Pinker, S. (1994). The Language Instinct: How the Mind Creates Language. New York: William Morrow.

Poels, K. \& Dewitte, S. (2006). How to Capture the Heart? Reviewing 20 Years of Emotion Measurement in Advertising. Journal of Advertising Research, 46, 18-37.

Reece, B. B. (1984). Children's Ability to Identify Retail Stores From Advertising Slogans. Advances in Consumer Research, 11, 320-323. 
Richins, M. L. (1997). Measuring emotions in the consumption experience. Journal of Consumer Research, 24, 127.

Rosengren, S. \& Dahlen, M. (2006). Brand-Slogan Matching in a Cluttered Environment. Journal of Marketing Communications, 12, 263-279.

Russell, J. A. \& Barrett, L. F. (1999). Core Affect, Prototypical Emotional Episodes, and Other Things Called Emotion: Dissecting the Elephant. [Article]. Journal of Personality \& Social Psychology, 76, 805-819.

Schuller, B., Rigoli, G. \& Lang, M. (2003). Hidden Markov Model-Based Speech Emotion Recognition. In International Conference on Acoustics, Speech, and Signal Processing 2003, Hong Kong China (pp. 401-405).

Shapiro, S., Maclnnis, D. J., \& Park, C. W. (2002). Understanding Program-Induced Mood Effects: Decoupling Arousal from Valence. Journal of Advertising, 31, 15-26.

Stout, P. A. \& Leckenby, J. D. (1986). Measuring Emotional Response to Advertising. Journal of Advertising, 15, 35-42.

Supphellen, M. \& Nygaardsvik, I. (2002). Testing Country Brand Slogans: Conceptual Development and Empirical Iflustration of a Simple Normative Model. Journal of Brand Management, 9, 385.

Tato, R. S., Kompe, R., \& Pardo, J. M. (2002). Emotional Space Improves Emotion Recognition. In International Conference on spoken Language Processing, Colorado USA (pp. 2029-2032).

Tull, D. \& Hawkins, D. (1987). Marketing Research. 4th ed. New York: Macmillan.

Vakratsas, D. \& Ambler, T. (1999). How Advertising Works: What Do We Really Know? Journal of Marketing, 63, 26-43.

Wells, W., John, B., \& Sandra, M. (1989). Advertising -Principal and Practice. New Jersey: PrenticeHall.

Winkielman, P., Berridge, K. C., \& Wilbarger, J. L. (2005). Unconscious Affective Reactions to Masked Happy Versus Angry Faces Influence Consumption Behavior and Judgments of Value. Personality and Social Psychology Bulletin, 31, 121-135.

Wright, D. E. \& Snow, R. E. (1980). Rituals and Ceremonies in Popular Culture. Ohio: Bowling Green University Popular Press.

Wurm, L. H., Vakoch, D. A., Strasser, M. R., Calin-Jageman, R., \& Ross, S. E. (2001). Speech perception and vocal expression of emotion. Cognition \& Emotion, 15, 831-852.

Zaltmann, G. (2003). How Customers Think. Boston, MA: Harvard Business School Press. 


\section{Resumo}

A forma como os slogans das marcas influenciam e modificam a percepçăo dos consumidores sobre a imagem dos produtos tem sido um tema de grande interesse para os especialistas de marketing. No entanto, não é tarefa fácil avaliar o efeito produzido pelos slogans de marcas nas emoções dos consumidores, nem o modo como estas influenciam a percepção dos clientes. Neste estudo, com a demonstração do Slogan Validator, são avaliados os slogans de marcas, procurando-se analisar o discurso dos slogans sonoros. O objectivo consiste na avaliação se a técnica de reconhecimento dos sinais emocionais podem servir de complemento aos métodos tradicionais de pesquisa, tais como investigação fenomenologica baseada em medidas fisiológicas e entrevistas semi-estruturadas, no sentido de aumentar a eficácia das estratégias de publicidade. Os resultados preliminares da experiência demonstraram que o Slogan Validator apresenta uma forte consistência na percepção actual dos participantes sobre os slogans de marcas escoIhidos para este estudo.

Palauras-chave: Slogans de marcas; reconhecimento de emoçōes; reconhecimento do discurso; processo de aprendizagern. 